\title{
Socioeconomic aspects of arrhythmias treatment in Poland in comparison with other EU countries- systematic report.
}

Radosław Sierpiński 1, B-D, Jakub Gierczyński², A-C, E, Małgorzata Gałązka- Sobotka, A, Jan Gryglewicz, B-C,

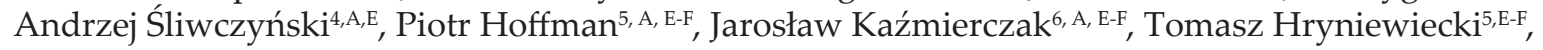
Łukasz Jan Szumowski ${ }^{5, A-F}$

A - Research concept and design, B - Collection and/or assembly of data, C - Data analysis and interpretation,

D - Writing the article, E - Critical revision of the article, F - Final approval of article

1 Institute of Cardiology

2 National Institute of Public Health - National Institute of Hygiene, Warsaw, Poland

Institute of Management in Health Care, Lazarski University, Warsaw, Poland

3 Institute of Management in Health Care, Lazarski University, Warsaw, Poland

4 National Health Fund

5 Institute of Cardiology in Warsaw

6 Pomeranian Medical University, Poland

Address for correspondence:

Radosław Sierpiński, Institute of Cardiology

email: rsierpinski@ikard.pl

Jakub Gierczyński, National Institute of Public Health - National Institute of Hygiene, Warsaw, Poland email: j.gier@hotmail.com

Małgorzata Gałązka- Sobotka, Institute of Management in Health Care, Lazarski University, Warsaw, Poland email: m.galazka-sobotka@lazarski.edu.pl

Jan Gryglewicz, Institute of Management in Health Care, Lazarski University, Warsaw, Poland

email: j.gryglewicz@lazarski.edu.pl

Andrzej Śliwczyński, National Health Fund

email: Andrzej.Sliwczynski@nfz.gov.pl

Piotr Hoffman, Institute of Cardiology in Warsaw

email: phoffman@ikard.pl

Jarosław Kaźmierczak, Pomeranian Medical University, Poland

email: jar.kazmierczak@o2.pl

Tomasz Hryniewiecki, Institute of Cardiology in Warsaw

email: thryniewiecki@ikard.pl

Łukasz Jan Szumowski, Institute of Cardiology in Warsaw

email: 1szumowski@ikard.pl

Received: 29.12.2016

Revised: 30.12 .2016

Accepted: 31.12 .2016

DOI: https://doi.org/10.24255/hbj/68127

\section{Key words:}




\section{Introduction}

Cardiac arrhythmia is a group of conditions in which the heart beats are irregular, too fast (tachyarrhythmias) or too slow (bradyarrhythmias). There are four main types of tachyarrhythmia : additional beats, tachycardia, flutter and fibrillation. All of the above can occur in the atria, ventricles, or can involve both atria and ventricles. The most common form of arrhythmia is atrial fibrillation, so in this article it will be the basic arrhythmia model.

Invasive treatment of tachyarrhythmias is mainly based on catheter ablation (CA). In the case of atrial fibrillation ablation the main goal of ablation is to isolate the ostia of the pulmonary veins from the left atrium using a point-by-point technique or cryoballoon. In current clinical electrophysiology (EP) numerous effective concepts regarding the diagnosis and treatment of arrhythmias have been introduced. A further improvement in the cost-benefit and the cost-effectiveness ratio in cardiac electrophysiology depends on the technical progress and on the funding mechanisms. The broader clinical use of the new techniques makes it possible to optimize the costs for care of patients with cardiac arrhythmias.

There is a lack of information on interventional treatment of arrhythmias in Poland and high demand for validated in- according to the European Heart Rhythm Association (EHRA) White Book 2016 (data for Poland were submitted by Prof J. Kaźmierczak, National Consultant for Cardiology).

\section{Financial aspects of arrhythmia treatment in poland in the years 2014-2015}

In 2014 the National Health Fund (NHF) financed the provision of health care for patients with diagnoses of paroxysmal tachycardia (according to ICD10, I47), atrial fibrillation and atrial flutter (I48) and other cardiac arrhythmias (I49) in the amount of more than PLN 274.8 million. In 2015 NHF expenditures amounted to almost PLN 300 million, and thus increased annually by $8.7 \%$. The data are presented in Table 1 .

According to NHF data, in 2014, 26842 patients were treated for paroxysmal tachycardia. There were 61889 hospitalizations and procedures related to outpatient specialist care. The total cost of the above was approximately PLN 3.3 million. In 2015 the same parameters slightly changed - 25893 patients treated for paroxysmal tachycardia with 63745 provisions of hospitalizations and outpatient specialist care that valued approximately PLN 3.5 million (Table 1).

Atrial fibrillation (AF) is responsible for most arrhythmia-related hospital admissions and is the most common

Table 1. Number and value of procedures financed by the National Health Fund in the $2014-2015$ for health care services in patients with tachyarrhythmias ${ }^{1}$.

\begin{tabular}{|c|c|c|c|c|c|}
\hline Arrhythmia & ICD-10 & Year & $\begin{array}{c}\text { Number of } \\
\text { patients treated }\end{array}$ & $\begin{array}{c}\text { Number of } \\
\text { health benefits }\end{array}$ & Value in PLN \\
\hline \multirow{2}{*}{ Atrial fibrillation/ flutter } & \multirow{2}{*}{148} & 2014 & 253872 & 1265984 & 243522369,60 \\
\hline & & 2015 & 265538 & 1299593 & 266053478,95 \\
\hline \multirow{2}{*}{ Supraventricular tachycardia } & \multirow{2}{*}{147} & 2014 & 26842 & 61889 & 3296952,19 \\
\hline & & 2015 & 25893 & 63745 & 3537888,52 \\
\hline \multirow{2}{*}{ Other arrhythmias } & \multirow{2}{*}{149} & 2014 & 223720 & 440799 & 27992859,18 \\
\hline & & 2015 & 224687 & 473552 & 29128544,44 \\
\hline \multirow{2}{*}{ Overall } & \multirow{2}{*}{ N/A } & \multicolumn{3}{|c|}{2014} & 274812180,97 \\
\hline & & \multicolumn{3}{|c|}{2015} & 298719911,90 \\
\hline
\end{tabular}

Source: Szumowski Ł, Gierczyński J, Gałązka-Sobotka M, et al.: Raport Aspekty kliniczne, ekonomiczne i systemowe z elementami modelowych rozwiązań w zakresie koordynacji opieki nad pacjentami w Polsce. Uczelnia Łazarskiego, Warszawa, 2016- in press.

formation, so there is a strong need to prepare an innovative and comprehensive systemic report about the current status of EP care in Poland. In 2016 a group of experts from different interested parties (Łazarski University, National Health Fund - NHF, cardiologists, and the Polish Social Insurance Institution (ZUS)) as a response to that need prepared such a report and intend to present the partial results of that study ${ }^{[1]}$.

The methodology of the report was based on collection of the source data from the public payer - the NHF (medical benefits) and ZUS (social benefits) - according to ICD-10 groups (I47-I49) and GRD (therapeutic procedures) codes (E39, E41, E43, E44, E45). All data were presented in PLN (Euro exchange rate - PLN 4.40). Arrhythmia statistics comparing Poland, the Czech Republic, Germany and France were presented cause of ischemic stroke. AF has a high negative impact on the quality of life (QoL) and is associated with increased mortality. Its prevalence is rising in the EU's ageing society ${ }^{[2]}$ and so are the expenses related to its management ${ }^{[3]}$ and productivity loss among the suffering patients $\mathrm{s}^{[4]}$. Patients with persistent or longstanding atrial fibrillation have modest success achieving sinus rhythm with catheter ablation or rhythm control medications. Their high risk of stroke, bleeding, and heart failure leads to significant morbidity and health care costs.

In 2014 and 2015 over 250000 patients were treated for atrial fibrillation and flutter and in both years had over $1 \mathrm{~m}$ healthcare provisions and procedures granted under outpatient specialist care with the reimbursement of up to approximately PLN 250 million. 
In 2014 and 2015 the numbers of patients with other arrhythmias (I49 - arrhythmia unspecified elsewhere) were 223720 and 224687 respectively. The number of hospitalizations and procedures granted under outpatient specialist care were 440799 and 473552 respectively, and the total reimbursement cost was PLN 27.9 vs 29.1 m respectively.

\section{Number and value of reimbursed ablation procedures in the years 2014-2015}

In 2014 and 2015 the NHF reimbursed a total of 11713 and 12587 ablation procedures, respectively (annual growth of $7.46 \%$ ). Most procedures were marked as E41 - 3D ablation of arrhythmias: 4860 in 2014 and 5239 in 2015. There was therefore an annual increase of $7.8 \%$ of $3 \mathrm{D}$ procedures. The second largest reimbursed group was E43 - ablation of arrhythmias, with 4447 and 4370 procedures respectively in 2014 and 2015 (Table 2).

In 2014 the NHF settled the provision of ablation treatment in the total amount of PLN 230672 854, whereas in 2015 the total amount was PLN 253366 199. Therefore the annual increase of reimbursement was $9.84 \%$.

The highest reimbursement was spent on 3D ablations (E41 in diagnosis-related group, DRG) - PLN 124528108 in 2014

\section{Ablation in Poland}

In Poland, ablation procedures are performed in 85 centers, both large clinical centers and smaller cardiac centers. Data on the availability of ablation procedures in Poland compared to other European countries are presented in Table 3.

\begin{tabular}{|c|c|c|c|c|}
\hline Category & Poland & $\begin{array}{c}\text { Czech } \\
\text { Republic }\end{array}$ & Germany & France \\
\hline $\begin{array}{l}\text { Overall number of } \\
\text { procedures }\end{array}$ & 10922 & 5855 & 33420 & 33300 \\
\hline $\begin{array}{l}\text { Number of proce- } \\
\text { dures (per } 1 \mathrm{mln} \\
\text { people) }\end{array}$ & 284 & 550 & 413 & 503 \\
\hline
\end{tabular}

Source: Kaźmierczak J, EHRA White Book 2016

The most active countries in Northern, Western, Southern, and Eastern Europe in 2015 were Denmark (703 ablations per million inhabitants), Germany (789), Slovenia (359), and the

\begin{tabular}{|c|c|c|c|c|c|}
\hline DRG & 2014 & 2015 & 2014 & 2015 & \% 2015 vs. 2014 \\
\hline E39 Ablation in $<18$ y.o & 457 & 514 & 12807961 & 14449349 & $112,82 \%$ \\
\hline E41 Electroanatomical 3D ablation & 4860 & 5239 & 124528108 & 134628337 & $108,11 \%$ \\
\hline E43 Classical ablation & 4447 & 4370 & 67293390 & 67266795 & $99,96 \%$ \\
\hline E44 Cryoablation & 1170 & 1248 & 7704018 & 8305888 & $107,81 \%$ \\
\hline E45 Cryobaloon ablation of atrial fibrillation & 779 & 1216 & 18339377 & 28715830 & $156,58 \%$ \\
\hline Overall & 11713 & 12587 & 230672854 & 253366199 & $109,84 \%$ \\
\hline
\end{tabular}

Source: Szumowski Ł, Gierczyński J, Gałązka-Sobotka M, et al.: Raport Aspekty kliniczne, ekonomiczne i systemowe z elementami modelowych rozwiązań w zakresie koordynacji opieki nad pacjentami w Polsce. Uczelnia Łazarskiego, Warszawa, 2016- in press.

and PLN 134628337 in 2015 (increase of 8.11\%). The second largest expenditure of the NHF was the E43 group - classical ablation, which in 2014 issued PLN 67293390 and in 2015 PLN 67266795.

\section{Access to ablation treatment in poland in the relation to the european union countries}

Ablation is always preceded by an electrophysiological study (EPS), the aim of which is to find the source of arrhythmia and confirm its mechanism. After EPS the ablation procedure takes place. Usually, for simplicity, both parts of the procedure - electrophysiological study and ablation, are called simply ablation.
Czech Republic (578), respectively. In 2015, the rate of ablations per million population increased in most of the european countries. The growth in the mean ablation rate per million population was highest in the Eastern and Southern European regions. In Slovenia, the increase in the ablation rate was $63 \%{ }^{[5]}$

\section{Atrial fibrillation ablation}

In accordance with the recommendations of the Society of Cardiology, patients with symptomatic atrial fibrillation refractory to medical therapy are qualified for ablation. In this case, ablation is indicated in the highest level of recommendations ${ }^{[6]}$. The treatment must also be considered in patients with symptomatic arrhythmia as an alternative to medication (no drug treatment sample) and in patients in whom atrial fibrillation impairs the function of the left ventricle. It should 


\begin{tabular}{|c|c|c|c|c|}
\hline Category & Poland & $\begin{array}{l}\text { Czech } \\
\text { Republic }\end{array}$ & Germany & France \\
\hline $\begin{array}{l}\text { Overall number of } \\
\text { procedures }\end{array}$ & 2169 & 2297 & 11697 & 11000 \\
\hline $\begin{array}{l}\text { Number of proce- } \\
\text { dures (per } 1 \mathrm{mln} \\
\text { people) }\end{array}$ & 56 & 216 & 145 & 166 \\
\hline
\end{tabular}

Source: Kaźmierczak J, EHRA White Book 2016

be added that the effectiveness of drug treatment does not exceed $50 \%$ in the prevention of recurrence of arrhythmia.

According to the EHRA White Book ${ }^{[5]}$ in 2015, a total of 87527 atrial fibrillation (AF) ablations were performed in the 43 ESC countries that submitted AF ablation data for the EHRA White Book. The mean number of AF ablations per million inhabitants was 96, which is about the same as in 2014 (96 per million). The most active countries were Germany (416 AF ablations per million population), Denmark (337), and Belgium (289).

In the Eastern region, the AF ablations activity was extremely heterogeneous. The growth in $\mathrm{AF}$ ablation rate per million population was highest in Azerbaijan (197\%), Turkey (87\%), and Bulgaria (79\%), whereas in Armenia, Cyprus, and Serbia the $\mathrm{AF}$ ablation rate decreased by 91,81 , and $36 \%$, respectively.

\section{Ventricular tachycardia/ventricular fibrillation}

The candidates for ablation of complex ventricular arrhythmias are mainly patients with a damaged heart who have previously had an implantable cardioverter defibrillator (ICD) or cardiac resynchronization therapy defibrillator (CRTD) implanted. In accordance with the guidelines of the European Society of Cardiology, in the event of such an arrhythmia (also terminated by the implanted device) - due to the direct and serious threat to the patient's life - performing ablation is indicated at the highest level of recommendations [7]. Performing this procedure should be considered after the first episode of arrhythmia. The effectiveness of the ablation depends on the patient's condition and the development of the disease causing the arrhythmia (atherosclerosis or another episode of ischemia creates a new substrate for arrhythmias), but in the case of recurrent arrhythmia, regardless of efficiency, ablation is considered as life-saving. Data on the number of treatments carried out in Poland and Europe are presented in the table below.

In 2015, the number of centers performing more than 10 ventricular tachyarrhythmia ablations for patients with structural heart disease per million population was highest in Germany (1.71) and lowest in Ukraine (0.02). The mean number of VT/VF ablations per million population in the ESC countries increased from 9.2 in 2014 to 16.0 in 2015. It was highest in Germany (83 per million population) followed by Finland (30), the Czech Republic (28), and Denmark (26) ${ }^{[5]}$.
According to the EHRA White Book data, catheter ablation of VT has been one of the key areas of growth in electrophysiology in recent years.

\begin{tabular}{|c|c|c|c|c|}
\hline Category & Poland & $\begin{array}{l}\text { Czech } \\
\text { Republic }\end{array}$ & Germany & France \\
\hline $\begin{array}{l}\text { Overall number of } \\
\text { procedures }\end{array}$ & 693 & 297 & 6686 & 741 \\
\hline $\begin{array}{l}\text { Number of proce- } \\
\text { dures (per } 1 \mathrm{mln} \\
\text { people) }\end{array}$ & 18 & 28 & 83 & 11 \\
\hline
\end{tabular}

Source: Kaźmierczak J, EHRA White Book 2016

\section{CARDIAC ARRHYTHMIAS AS A CAUSE OF INABILITY TO WORK IN 2014}

Expenditure of the Social Insurance Institution (ZUS) on incapacity for work due to clinical diagnoses of paroxysmal tachycardia (ICD10 - I47), atrial fibrillation and atrial flutter (I48) and other cardiac arrhythmias (I49) in 2014 reached PLN 132 million. This value represented $0.4 \%$ of total expenses of ZUS related to disability.

Table 6. Total expenditure on benefits related to disability to work incurred in 2014

\begin{tabular}{|c|c|c|c|c|}
\hline \multirow{3}{*}{$\begin{array}{l}\text { Category } \\
\text { Overall }\end{array}$} & \multirow{3}{*}{$\begin{array}{l}\text { Overall } \\
\text { 147-149 } \\
132049,8\end{array}$} & 147 & 148 & 149 \\
\hline & & \multicolumn{3}{|c|}{ Amount in thousands PLN } \\
\hline & & 11076,8 & 74596,0 & 46377,0 \\
\hline $\begin{array}{l}\text { Pension due to } \\
\text { inability to work }\end{array}$ & 70305,3 & 4410,6 & 46927,7 & 18967,0 \\
\hline Social pensions & 857,3 & 260,6 & 307,4 & 289,3 \\
\hline $\begin{array}{l}\text { Rehabilitation } \\
\text { benefits }\end{array}$ & 6553,2 & 641,3 & 3800,5 & 2111,4 \\
\hline Sick leave & 54106,8 & 5726,9 & 23441,6 & 24938,3 \\
\hline $\begin{array}{l}\text { Rehabilitation } \\
\text { treatment }\end{array}$ & 227,0 & 37,2 & 118,8 & 71,0 \\
\hline
\end{tabular}

Source: ased on analysis by Karczewicz E, Zalewska H, The Polish Social Insurance Institution (ZUS),2016

The number of insured who in 2014 received at least one certificate issued in respect of paroxysmal tachycardia (I47) was 5.4 thousand, due to atrial fibrillation and flutter (I48) was 11.8 thousand, and due to other cardiac arrhythmias (I49) was 19.4 thousand. The average length of sick leave accumulated in the case of paroxysmal tachycardia (I47) amounted to 18.40 days, in the case of atrial fibrillation and atrial flutter (I48) it 
was 29.37 days, and in the case of other cardiac arrhythmias (I49) it was 18.12 days.

Expenditure on inability to work due to paroxysmal tachycardia (I47) was around PLN 11.1 million, atrial fibrillation and atrial flutter (I48) PLN 74.6 million, and other cardiac arrhythmias (I49) PLN 46.4 million.

\section{COST-EFFECTIVENESS OF ABLATION BASED ON THE EXAMPLE OF ATRIAL FIBRILLATION ABLATION}

The cost of conventional management of AF is significant. It has been calculated that the total cost burden of AF may be as much as $1 \%$ of the total health-care system expenditures in the United Kingdom ${ }^{[8]}$. A study from France included direct medical costs, pharmacological expenditures, and costs of thromboembolic and other complications ${ }^{[9]}$. Costs per year per patient were calculated at EUR 3300, and the main drivers were the cost of hospitalization (EUR 1300) and costs of heart failure therapy (EUR 1000). Expenses on treatment of stroke reached around EUR 330 per patient. Other European studies showed that the average yearly cost of conventional therapy varied within EUR 1010-3225 per year ${ }^{[10]}$. These findings are similar to the data observed in the study by Bulkova et al. evaluated for the Czech Republic, where the mean individual expenditure on conventional AF therapy was estimated at EUR 1462 per year ${ }^{[11]}$.

It is worth underlining that the average therapeutic costs may differ according to individual national economics and the level of health-care funding. Costs of conventional treatment of AF represent a reasonable burden for each European country economy. Some studies of cost of care of an AF patient have been published in an attempt to estimate the relative cost of ablation and contrast it to the cost of medical therapy over time.

According to the Anderson group study, after 5 years of observation, convergent procedure patients averaged 1.10 procedures, with $75 \%$ of survivors in sinus rhythm; catheter ablation patients had 1.65 procedures, with $49 \%$ in sinus rhythm. Compared to medical management, catheter ablation and the convergent procedure were cost-effective for the lower risk (incremental cost-effectiveness ratio [ICER] < USD 35,000) and medium risk (ICER $<$ USD 15,000) cohorts. The procedures dominated medical management for the higher risk cohort (lower cost and higher QALYs (quality-adjusted life years)). The convergent procedure dominated catheter ablation for all risk cohorts. The authors concluded that the convergent procedure results in superior maintenance of post-ablation sinus rhythm with fewer repeat ablation procedures compared to catheter ablation, leading to lower cost and higher QALYs after 5 years ${ }^{[12]}$.

The Ladapo study identified a total of 3,194 patients who had undergone catheter ablation for treatment of $\mathrm{AF}$, had continuous enrollment in the database 6 months prior to the first ablation, and had at least 1 year of post-ablation follow-up. Compared to the 6 months prior to ablation, there were significant reductions in the number of outpatient appointments, inpatient days, and emergency room visits in the total study population and in the subset aged $\geq 65$ years. There was a statistically significant $(\mathrm{P}<0.01)$ decrease in total healthcare expenditures across four of the five 6-month time periods, with annual savings ranging from USD 3,300 to USD 9,200. For patients aged $\geq 65$ years, annual savings ranged from USD 3,200 to USD 9,200. Drug utilization also significantly declined $(\mathrm{P}<0.01)$, with average annual medication savings ranging from USD 670 to USD 890, and from USD 740 to USD 880 for patients aged $\geq 65$ years. Catheter ablation for AF reduced healthcare utilization and expenditures up to 3 years after ablation ${ }^{[13]}$.

McKenna et al. analyzed the cost-effectiveness of radiofrequency catheter ablation for the treatment of atrial fibrillation in the United Kingdom. After the systematic review and meta-analysis of the data from the NHS system, the results showed that the ICER of radiofrequency catheter ablation (RFCA) varied between GBP 7763 and GBP 7910 for each additional QALY according to baseline risk of stroke, with a probability of being cost-effective from 0.98 to 0.99 for a cost-effectiveness threshold of GBP $20000^{[14]}$.

Costs related to medical therapy in the analysis included the cost of anticoagulation, rate and rhythm control medications, non-invasive testing, physician follow-up visits and hospital admissions, as well as the cost of complications related to this management strategy. Costs related to catheter ablation were assumed to include the cost of the ablation tools (electro anatomic mapping or intracardiac echocardiography-guided pulmonary vein ablation), hospital and physician billings, costs related to per procedural medical care and complications. Costs related to these various elements were obtained from the Canadian Registry of Atrial Fibrillation (CARAF), government fee schedules and published data. Sensitivity analyses assessing a range of initial success rates (50-75\%) and late attrition rates (1-5\%), prevalence of congestive heart failure (20-60\%) as well as discounting varying from 3 to $5 \%$ per year were performed. In this study, the cost of the catheter ablation strategy ranged from USD 14,000 to USD 18,000. It was assumed that patients who required anticoagulation prior to ablation would continue on this therapy following the procedure with an annual average follow-up cost of USD 1400 to USD 1800 among the ablated patients. The annual cost of medical therapy ranged from USD 3,600 to USD 4300. The study projected costs of ongoing medical therapy and catheter ablation to equalize at 3.2 to 8.4 years of follow-up ${ }^{[15,16]}$.

Reynolds and his group published a Markov model costeffectiveness analysis of ablation vs pharmacotherapy in a simulated cohort of patients with paroxysmal drug refractory AF projected over 5 years ${ }^{[17]}$. They assumed $60 \%$ success of the ablation approach with a $25 \%$ rate of reablation need. In the base scenario, the incremental cost per QALY among ablated patients was USD 47,333 with cost neutrality achieved at $~ 10$ years. While more expensive at first line, ablation appears to be a cost-effective alternative to the non-invasive $\mathrm{AF}$ treatment strategies after a 3-5 year time horizon. 
Eckard et al. developed a decision-analytic model to estimate costs, health outcomes and incremental cost-effectiveness of radiofrequency ablation compared to conventional drug therapy for AF with a lifetime time horizon ${ }^{[18]}$. The authors used a decision tree for the initial year in which the radiofrequency ablation procedure is assumed to take place. They observed $70-80 \%$ ablation success within the first year with 1.4 ablations per patient required to maintain rhythm based on Swedish data. The cost of ablation was estimated at around USD 12,000, including the cost of 3-4 days in hospital, all diagnostic examinations necessary as well as the cost of disposables. Annual cost of AF therapy was estimated at USD 2000. In order to estimate QALY weights for different health states, age-adjusted QALY weights based on a Swedish general population were applied for patients in the controlled AF state, and used as reference points. With annual success rates of $5 \%, 10 \%$ and $15 \%$ used in the sensitivity analysis, the relative cost of ablation was estimated up to USD 58000 per QALY without assuming stroke prevention related to the ablation strategy.

Chan et al., ${ }^{[19]}$ using a disease simulation Markov model, projected the potential costeffectiveness of $\mathrm{CA}$ for $\mathrm{AF}$, compared with amiodarone or rate control in a population of patients with low-to-moderate risk of stroke. Costs from a health service perspective and outcomes were measured as QALYs. They concluded that with an expected $80 \%$ efficacy rate for sinus rhythm restoration, the relative reduction in stroke risk would need to be 42 and $11 \%$ to yield ICER values of USD 50000 and USD 100000 per QALY, respectively. In other words, in patients at a low stroke risk CA is unlikely to be costeffective. However, this study did not consider potential improvements in quality-adjusted life expectancy due to maintenance of sinus rhythm alone. The most robust analysis of the costeffectiveness of radiofrequency CA for $\mathrm{AF}$ in comparison with antiarrhythmic drug (AAD) therapy was performed by a group of experts working for NICE in the United Kingdom ${ }^{[20]}$. They used a systematic review of the literature and meta-analysis, and applied Bayesian statistical methods to synthesize the effectiveness evidence from randomized controlled trials. A decision analytical model was developed to assess the costs and consequences associated with the primary outcome of the trials over a lifetime time horizon. Costs were again measured as QALYs. This study found that the ICER of CA varied between GBP 7763 and GBP 7910 for each additional QALY according to baseline risk of stroke, and with a probability of being costeffective from 0.98 to 0.99 (using a cost-effectiveness threshold of GBP 20000 ). This group concluded that CA is a potentially cost-effective strategy for paroxysmal $\mathrm{AF}$ in patients predominantly refractory to AAD therapy, provided the quality-of-life benefits are maintained for 5 years.

\section{SUGGESTED MODEL OF ELECTROPHYSIOLOGY CARE IN POLAND}

There is a need for concentration of highly specialized treatments in tertiary centers, which will also function as teaching centers for EP fellows. In addition, intensive financial mechanisms should be established to promote excellence and the highest quality of trained EP fellows in such centers. Moreover, in order to maintain professional care and safety, the reimbursement should depend on documented expertise in electrophysiology (certificates confirming the acquired experience). Such a system will help to maintain a high level of competence in performing the procedure as well as the teaching level. In the proposed model of the hospital EP network outpatient clinics are important links. The role of such clinics is to refer to the patient the risk-benefit ratio in individual patients who would gain most from an ablation procedure (a regular cardiologist might lack such expertise). The outpatient clinics should also prepare the patient for the invasive treatment in order to minimize the number of unnecessary hospitalizations (e.g. no anticoagulation or inadequate one, concomitant acute disease that might postpone the procedure), as well as doing all the possible and necessary diagnostic tests (e.g. echo, blood tests) in order to shorten the hospital stay. Last but not least is the quality control process. It is crucial to report the success rate as well as the complication rate in FU at least 3, 6 and 12 months after the procedure.

The final factor limiting access to ablation therapy is the way it is financed. This report shows NHF reimbursement in ablation of approximately PLN 250 million in 2015, which constituted approximately $7.8 \%$ of spending on the NHF on cardiovascular disease in general. It should be noted that the reduction in early mortality in acute coronary syndrome patients needed approximately PLN 1.8 billion spent by the NHF per year. Therefore it is very possible that the amount of approximately PLN 250 million (issued today by the NHF) for the treatment of cardiac arrhythmias may be inadequate for the health needs of the aging Polish population. The authors of the report 'Szumowski Ł, Gierczyński J, Gałązka-Sobotka M, et al. Uczelnia Łazarskiego, Warszawa, 2016 - in press' suggest that one solution that would increase the number of EP procedures would be to separate them, as high-cost procedures that are first stopped in hospitals, from the overall cardiology contract.

\section{Conclusions}

Treatment of cardiac arrhythmias by ablation therapy is highly efficient and safe. In many cases it can have a profound and sustained effect in eliminating arrhythmia. Ablation is the most effective and most modern treatment of cardiac arrhythmias, reducing the risk of heart failure and stroke. In Poland there is a shortage of adequate funding for ablation therapy as clinically appropriate. The potential of Polish centers and substantive preparation of medical personnel can protect medical needs of patients by increasing the expenditure on ablation procedures and the lack of limits on the NHF contracts for health services in this area. It requires expensive equipment and extensive experience of physicians performing the procedures. This translates into early cost of treatment, but according to the above considerations will provide savings in the long-term time horizon. 
Currently, the NHF reimburses approximately PLN 250 million per year by financing ablation procedures. It would not ensure the health needs of all patients with arrhythmias eligible for this treatment. It generates difficult to estimate expenses for the treatment of stroke and heart failure and ad hoc expenditures due to the work of rescue teams and medical cardioversions of approximately PLN 55 million per year. Through the lack of effective treatment the indirect costs of approximately PLN 130 million per year are generated for the National Insurance Company (ZUS). In order to secure high quality of ablation procedures in Poland, there is a need for concentration of highly specialized treatments in reference centers, which will also function as training centers.

It is worth underlining that there is good hardware infrastructure with highly specialized personnel. One way to increase the availability of ablation, particularly difficult procedures, would be to differentiate perceived centers of reference and focus them to perform complex ablations that require the most experienced specialists. At the same time it is necessary to increase global spending on ablations to take advantage of the existing potential, which is largely limited by the size of the contract concluded with the NHF. The catalog of guaranteed benefits requires a strong reconstruction in the field of ablation. It should be remembered that the treatment of arrhythmias should also be considered in a broader context - from eliminating the causes of arrhythmias, through its early detection with the participation of general practitioners and other specialists (not only cardiologists), to the ablation procedure and post-ablation care.

\section{References}

1. Szumowski Ł, Gierczyński J, Gałązka-Sobotka M, et al.: Raport Aspekty kliniczne, ekonomiczne i systemowe $\mathrm{z}$ elementami modelowych rozwiązań w zakresie koordynacji opieki nad pacjentami w Polsce. Uczelnia Łazarskiego, Warszawa, 2016 - in press.

2. Kannel WB, Wolf PA, Benjamin EJ, et al. Prevalence, incidence, prognosis, and predisposing conditions for atrial fibrillation: population-based estimates. Am J Cardiol 1998;82(8A): 2N-9N.

3. Stewart S, Murphy NF, Walker A, et al. Cost of an emerging epidemic: an economic analysis of atrial fibrillation in the UK. Heart 2004; 90(3): 286-92.

4. Reinhold T, Lindig C, Willich SN, et al. The costs of atrial fibrillation in patients with cardiovascular comorbidities - a longitudinal analysis of German health insurance data. Europace 2011; 13(9): 1275-80.

5. Hindricks G, Camm J, Merkely B, et al. The EHRA White Book. 2016. (http://www.escardio.org/communities/EHRA/ publications/Documents/ehra-whitebook-2016.pdf)

6. Kirchhof P, Benussi S, Kotecha D et al. 2016 ESC Guidelines for the management of atrial fibrillation developed in collaboration with EACTS. European Heart Journal (2016) 37, 2893-2962

7. Priori SG, Blomström-Lundqvist C, Mazzanti A et al. 2015 ESC Guidelines for the management of patients with ventricular arrhythmias and the prevention of sudden cardiac death European Heart Journal (2015) $36,2793-2867$

8. Stewart S, Murphy NF, Walker A, et al. Cost of an emerging epidemic: an economic analysis of atrial fibrillation in the UK. Heart 2004;90: 286-92.

9. Moeremans $\mathrm{K}$, Aliot E, Chillou $\mathrm{C}$ et. al. Second line pharmacological management of paroxysmal and persistent atrial fibrillation in France: a cost analysis. Value Health 2000;6:407-16.

10. Le Heuzey JY, Paziaud O, Piot O, et al. Cost of care distribution in atrial fibrillation patients: the COCAF study. Am Heart J 2004;147: 121-126.

11. Bulkova V, Fiala M, Chovancik J, et al. Conventional treatment of atrial fibrillation in the Czech Republic managed by outpatient cardiologist. Overview of diagnostic and treatment procedures, pharmacological treatment and hospitalisation. Vnitr Lek 2008;54:36-44.

12. Louise H. Anderson, Edward J. Black, Kenneth C. Civello et al. Cost-effectiveness of the convergent procedure and catheter ablation for non-paroxysmal atrial fibrillation Pages 481-491

13. Joseph A. Ladapo healthcare utilization and expenditures in patients with atrial fibrillation treated with catheter Ablation J Cardiovasc Electrophysiol, Vol. 23, pp. 1-8, January 2012

14. McKenna C, Palmer S, Rodgers M, et al. Cost-effectiveness of radiofrequency catheter ablation for the treatment of atrial fibrillation in the United Kingdom. Heart. 2009 Apr;95(7):542-9.

15. Khaykin Y, Morillo CA, Skanes AC et al. Cost comparison of catheter ablation and medical therapy in atrial fibrillation. J Cardiovasc Electrophysiol. 2007;18(9):907-

16. Khaykin $Y$, Wang X, Natale A, et al. Cost comparison of ablation versus antiarrhythmic drugs as first-line therapy for atrial fibrillation: an economic evaluation of the RAAFT pilot study. J Cardiovasc Electrophysiol 2009; 20(1): 7-12.

17. Reynolds MR, Zimetbaum P, Josephson ME, et al. Cost-effectiveness of radiofrequency catheter ablation compared with antiarrhythmic drug therapy for paroxysmal atrial fibrillation. Circ Arrhythm Electrophysiol. 2009;2(4):362-9.

18. Eckard N, Davidson T WH, LA L. Cost-effectiveness of catheter ablation treatment for patients with symptomatic atrial fibrillation. J A Fib 2009; 1(8): 461-70.

19. Chan PS, Vijan S, Morady F et al. Cost-effectiveness of radiofrequency catheter ablation for atrial fibrillation. J Am Coll Cardiol 2006;47:2513-20.

20. Rodgers M, McKenna C, Palmer S et al. Curative catheter ablation in atrial fibrillation and typical atrial flutter: systematic review and economic evaluation. Health Technol Assess 2008; 12:iii-iv, xi-xiii, 1-198. 